\title{
Kebersihan Perorangan dan Kecacingan pada Siswa SDN 128 Pekanbaru
}

\author{
Nila Puspita Sari, Zahratul Hayati \\ Prodi Sarjana Kesehatan Masyarakat, STIKes Hang Tuah Pekanbaru
}

\begin{abstract}
Abstrak
Latar Belakang: Infeksi cacing kerap menjadi permasalah bagi anak sekolah. Aktivitas bermain pada anak yang tidak memperdulikan kondisi higiene perorangan dan lingkungan sekitarnya. Cacingan berakibat buruk pada kemampuan anak dalam menerima dan mengikuti pelajaran di sekolah. Tujuan penelitian untuk mengetahui hubungan higiene perorangan dengan kejadian kecacingan pada siswa sekolah dasar

Metode: Penelitian ini merupakan studi kuantitatif dengan desain cross sectional. Populasi penelitian adalah siswa SDN 128 Pekanbaru kelas 2,3 dan 4, dengan sampel sebanyak 47 orang (purposive sampling). Dilakukan analisis data dengan uji chi-square dan menggunakan kuesioner sebagai alat ukur, pemeriksaan laboratorium, serta pengolahan data menggunakan komputerisasi.

Hasil: Penelitian ini menunjukkan bahwa cuci tangan pakai sabun, pengunaan alas kaki, kebersihan jari kuku, jajan sembarangan, dan bermain tanah $(P$ value $=0,001 ; 0,002 ; 0,001 ; 0,003 ; 0,001)$ memiliki hubungan dengan kecacingan pada siswa sekolah dasar di SDN 128 Kota Pekanbaru.

Kesimpulan: Dinas Kesehatan diharapkan adanya kerjasama dengan Puskesmas dan Pihak Sekolah untuk memberikan pembinaan, penyuluhan, dan pemberian obat cacing berkala pada siswa sekolah dasar agar terhindar dari risiko penyakit cacingan.
\end{abstract}

Kata Kunci: Kebersihan Perorangan, Kecacingan, Siswa Sekolah Dasar.

\section{Personal Hygiene and Helminthiasis of Primary School Students 128 in Pekanbaru}

\begin{abstract}
Background: An elementary school student is very vulnerable to helminthiasis infections, this is caused by their habit of playing and they usually do not pay attention to their hygiene and environment. These can cause affect the children able to receive and attend the school lessons. This study aimed to determine the relationship between personal hygiene and helminthiasis at elementary students.

Methods: This research used a quantitative method with a cross-sectional design, with respondents SDN 128 Pekanbaru. Populations were students of SDN 128 Pekanbaru at 2nd, 3rd, and 4th grade and samples are 47 people (purposive sampling). Data analysis used chi-square test, questionnaire, laboratory test, and processing data using computerization.

Result: This research showed that there as a correlation between washing hand with soap, using footwear, nails hygiene, eating ransom snack, and playing on the ground $(P$ value $=0,001 ; 0,002 ; 0,001 ; 0,003 ; 0,001)$ with the incidence of helminthiasis.

Conclusion: Suggested to the nearest institution which is the health service, hoped to assume the operation with the health center and the school to provide counseling and giving o worm medicines regularly to elementary students to prevent the incidence of helminthiasis.
\end{abstract}

Key words: Personal Hygiene, Helminthiasis, Primary School Student.

Korespondensi: Nila Puspita Sari

Email : nps@htp.ac.id 


\section{PENDAHULUAN}

Gangguan kesehatan dan penurunan mutu sumber daya manusia dapat disebabkan oleh penyakit cacingan, yang disebabkan oleh cacing pada usus manusia sehingga dapat menghisap makanan dan darah di dalamnya. Penderita penyakit ini akan mengalami kurang gizi dan kurus, dan penderita mudah lelah, penurunan daya tangkap untuk menurunkan produktivitas. ${ }^{1}$ Sebanyak $24 \%$ dari populasi penduduk dunia atau sekitar 1,5 milyar orang masih terinfeksi Soil Transmitted Helminthes dan terdapat banyak anak usia pra sekolah dan usia sekolah membutuhkan pengobatan. Daerah dengan iklim tropis (panas dan lembap) dan subtropis dengan kondisi sanitasi lingkungan yang buruk, menyebabkan cacing berkembang biak dengan baik sehingga prevalensi kecacingan masih sangat tinggi. Aktivitas kontak langsung atau tertelan larva atau telur cacing dari tanah yang terkontaminasi menjadi salah satu faktor penyebabnya. ${ }^{2,5}$

Angka Prevalensi anak Sekolah Dasar yang mengalami kecacingan di Indonesia yaitu sekitar 60-80\%. Hasil pemeriksaan feses (tinja) anak sekolah yang dilakukan di 10 kabupaten/kota di Indonesia ditemukan 829 anak posistif cacingan dari 3.666 siswa dari 64 SD yang diperiksa (Prevalensi 22,6\%) ${ }^{3}$. Sebanyak 201 siswa di Kabupaten Siak, ditemukan sebanyak 19 siswa $(9,5 \%)$ positif. Kota Dumai juga ditemukan 33 siswa $(16,5 \%)$ positif kecacingan dari 200 siswa sampel feses yang diperiksa. ${ }^{4}$

Rendahnya kesadaran untuk menjaga kebersihan perorangan dan lingkungan sekitar menjadi sasaran infeksi cacing bagi anak-anak dan orang dewasa. Minimnya perhatian dan tingkat pemahaman orangtua semakin meningkatkan risiko penularan infeksi cacing pada anak. Selain itu, minimnya pengetahuan masyarakat terkait hidup sehat juga mempengaruhi terjadinya infeksi. Cacing dapat menginfeksi melalui oral dengan tangan yang kotor atau tidak bersih, kemudian digunakan untuk mengkonsumsi makanan atau penggunaan air yang tercemar. Berbagai infeksi dapat terjadi akibat lingkungan yang lembap dan kotor, sumber air tercemar, dan rendahnya pengetahuan serta perilaku untuk hidup sehat. ${ }^{5}$
Kebersihan perorangan sangat berpengaruh terhadap kejadian infeksi penyakit khususnya pada anak-anak yang senang bermain dengan tanah, karena tanah merupakan temapat untuk cacing bertelur dan berkembangbiak. ${ }^{6}$ Salah satu penyebab anak terinfeksi cacingan adalah kebiasaan cuci tangan tanpa menggunakan sabun atau desinfektan. Selain itu, kebiasaan memotong kuku tangan dan kaki juga sering dikaitkan dengan masalah penyakit cacingan. ${ }^{7}$ Cacing pada anak dapat mengganggu pertumbuhan dan imunitas tubuh, sehingga anakanak rentan terserang penyakit. ${ }^{8}$

Bersamaan dengan dilakukannya program Bulan Imunisasi Anak Sekolah (BIAS) setiap 2 kali dalam setahun, Dinas Kesehatan Kota (DKK) Pekanbaru juga melakukan pemeriksaan feces pada siswa SD/MI se-Kota Pekanbaru. Kasus kecacingan ditemukan dari Puskesmas Muara Fajar sebanyak 79 kasus Tahun 2016 pada siswa SD/MI di Kota Pekanbaru, Diantara tiga sekolah yang ada di wilayah Muara Fajar yaitu SDN 128 Pekanbaru, SDN 59 Pekanbaru dan SDN 174 Pekanbaru, diperoleh kasus kecacingan pada siswa SD/MI yang tertinggi terdapat di SDN 128 Pekanbaru yaitu 59 anak dari total seluruh kasus 79 anak. Hasil observasi awal yang dilakukan di SDN 128 Pekanbaru yang terletak di Jalan Tengku Kasim Perkasa, didapati sebagian siswa/i di SDN 128 pada saat jam istirahat bermain di lingkungan sekolah dengan kondisi lapangan terbuka dan didapati mereka bertelanjang kaki, kontak langsung dan bermain tanah, memiliki kuku yang panjang dan hitam dan setelah bermain langsung mengkonsumsi makanan tanpa cuci tangan pakai sabun. Kondisi tangan yang tidak bersih berkemungkinan untuk ditemukan telur cacing yang kemudian akan ikut tertelan saat mengkonsumsi makanan. Kemudian terlihat ada beberapa siswa/i SDN 128 yang kurang aktif bergerak pada saat jam isitirahat dan anak-anak tersebut menunjukkan gejala kecacingan seperti badan kurus, perut buncit, dan lemas. Tujuan dari studi ini adalah untuk mengetahui apakah ada hubungan kebersihan perorangan dengan kecacingan pada siswa SDN 128 Pekanbaru. 


\section{METODE}

Jenis penelitian ini merupakan studi kuantitatif dengan desain cross sectional. Lokasi penelitian di SDN 128 Pekanbaru. Populasi pada studi ini adalah 90 orang atau seluruh siswa pada kelas II, III, dan IV dan sampel penelitian sebanyak 47 orang dengan mengumpulkan sampel feses dan kuesioner secara purposive sampling. Teknik ini diambil dengan pertimbangan bahwa siswa kelas II, III, dan IV dianggap masih belum bisa menjaga kebersihan diri sendiri. Data yang digunakan adalah data primer dengan pengumpulan data langsung melalui responden penelitian. Analisis data menggunakan uji statistik chi-square.

\section{HASIL}

Kebiasaan mencuci tangan pakai sabun diketahui telah dilakukan oleh 35 orang $(74,5 \%)$ dan 12 orang $(25,5 \%)$ tidak melakukan cuci tangan pakai sabun. Responden memiliki kebiasaan untuk menggunakan alas kaki sebanyak 38 orang $(80,9 \%)$ dan hanya 9 orang $(19,1 \%)$ tidak memakai alas kaki. Diketahui juga bahwa sebanyak 33 orang $(70,2 \%)$ memiliki kuku yang bersih dan terdapat 14 orang $(29,8 \%)$ yang tidak memiliki kuku yang bersih. Untuk kebiasaan jajan sebanyak 26 orang $(55,3 \%)$ mengaku tidak jajan sembarangan dan 21 orang lainnya $(44,7)$ mengaku suka jajan sembarangan. Sebanyak 26 orang $(55,3 \%)$ siswa tidak suka bermain tanah dan 21 orang lainya $(44,7 \%)$ suka bermain tanah.Berdasarkan uji analisis bivariat, diketahui bahwa terdapat hubungan yang signifikan antara mencuci tangan pakai sabun $(p$ value $=0,001)$, memakai alas kaki ( $p$ value $=$ 0,002 ), kebersihan kuku ( $\mathrm{p}$ value $=0,001$ ), jajan sembarangan ( $p$ value $=0,003)$, kebiasaan bermain tanah $(p$ value $=0,001)$ dengan kejadian kecacingan pada siswa di SDN 128 Pekanbaru.

Tabel 1. Hasil Analisis Bivariat Kejadian Kecacingan pada Siswa SD

\begin{tabular}{|c|c|c|c|c|c|c|c|c|}
\hline \multirow{3}{*}{ Variabel } & \multicolumn{4}{|c|}{ Kejadian Kecacingan } & \multirow{2}{*}{\multicolumn{2}{|c|}{ Total }} & \multirow{3}{*}{$\begin{array}{c}\text { OR } \\
95 \% \mathrm{CI}\end{array}$} & \multirow{3}{*}{$P$-value } \\
\hline & \multicolumn{2}{|c|}{ Positif } & \multicolumn{2}{|c|}{ Negatif } & & & & \\
\hline & $\mathbf{N}$ & $\%$ & $\mathbf{n}$ & $\%$ & $\mathbf{N}$ & $\%$ & & \\
\hline \multicolumn{9}{|c|}{ Mencuci Tangan Pakai Sabun } \\
\hline $\begin{array}{l}\text { Tidak } \\
\text { Ya }\end{array}$ & $\begin{array}{l}9 \\
7\end{array}$ & $\begin{array}{l}75 \\
20\end{array}$ & $\begin{array}{c}3 \\
28\end{array}$ & $\begin{array}{l}25 \\
80\end{array}$ & $\begin{array}{l}12 \\
35\end{array}$ & $\begin{array}{l}100 \\
100\end{array}$ & $\begin{array}{c}12,000 \\
(2,555-56,370)\end{array}$ & 0,001 \\
\hline \multicolumn{9}{|c|}{ Memakai Alas Kaki } \\
\hline $\begin{array}{l}\text { Tidak } \\
\text { Ya }\end{array}$ & $\begin{array}{l}9 \\
7\end{array}$ & $\begin{array}{l}77,8 \\
23,7\end{array}$ & $\begin{array}{c}2 \\
29\end{array}$ & $\begin{array}{l}22,2 \\
76,3\end{array}$ & $\begin{array}{c}9 \\
38\end{array}$ & $\begin{array}{l}100 \\
100\end{array}$ & $\begin{array}{c}11,728 \\
(1,979-64,276)\end{array}$ & 0,002 \\
\hline \multicolumn{9}{|c|}{ Kebersihan Kuku } \\
\hline $\begin{array}{l}\text { Tidak } \\
\text { Ya }\end{array}$ & $\begin{array}{c}11 \\
5\end{array}$ & $\begin{array}{l}78,6 \\
15,2\end{array}$ & $\begin{array}{c}3 \\
28\end{array}$ & $\begin{array}{l}21,4 \\
84,8\end{array}$ & $\begin{array}{l}14 \\
33\end{array}$ & $\begin{array}{l}100 \\
100\end{array}$ & $\begin{array}{c}20,533 \\
(4,178-100,915)\end{array}$ & 0,001 \\
\hline \multicolumn{9}{|c|}{ Jajan Sembarangan } \\
\hline $\begin{array}{l}\text { Tidak } \\
\text { Ya }\end{array}$ & $\begin{array}{c}12 \\
4\end{array}$ & $\begin{array}{l}57,1 \\
15,4\end{array}$ & $\begin{array}{c}9 \\
22\end{array}$ & $\begin{array}{l}42,9 \\
84,6\end{array}$ & $\begin{array}{l}21 \\
26\end{array}$ & $\begin{array}{l}100 \\
100\end{array}$ & $\begin{array}{c}0,136 \\
(0,035-0,538)\end{array}$ & 0,003 \\
\hline \multicolumn{9}{|c|}{ Bermain di Tanah } \\
\hline $\begin{array}{l}\text { Ya } \\
\text { Tidak }\end{array}$ & $\begin{array}{c}14 \\
2\end{array}$ & $\begin{array}{c}66,77 \\
, 7\end{array}$ & $\begin{array}{c}7 \\
24\end{array}$ & $\begin{array}{l}33,3 \\
92,3\end{array}$ & $\begin{array}{l}21 \\
26\end{array}$ & $\begin{array}{l}100 \\
100\end{array}$ & $\begin{array}{c}0,042 \\
(0,008-0,229)\end{array}$ & 0,001 \\
\hline
\end{tabular}




\section{PEMBAHASAN}

\section{Hubungan Cuci Tangan Pakai Sabun (CTPS) dengan Kecacingan pada Siswa SDN 128 Pekanbaru}

Berdasatkan analisis data yang dilakukan diketahui bahwa antara kebiasaan mencuci tangan pakai sabun dengan kejadian kecacingan terdapat hubungan dengan nilai $\mathrm{p}=0,001 \quad(<0,05)$. Diketahui bahwa responden yang tidak mencuci tangan pakai sabun berisiko 12 kali lebih tinggi untuk terkena kecacingan. Hal ini didukung oleh penelitian Avianti terkait personal hygiene dan keberadaan telur cacing dalam kotoran kuku pada siswa SDN 002 Kecamatan Mandau Duri yang menyatakan bahwa kebiasaan tidak cuci tangan pakai sabun menyajdi penyebab kecacingan karena kebiasaan anak-anak yang langsung memasukkan tangan ke dalam mulut tanpa cuci tangan pakai sabun. (nilai $\mathrm{p}=0,001$ dan $\mathrm{OR}=$ $54,44)$

Tangan digunakan untuk menyentuh berbagai macam benda, untuk makan, dan juga untuk membersihkan kotoran setelah buang air besar. Cuci tangan sebaiknya dilakukan dengan menggunakan sabun dan air bersih yang mengalir. Hal tersebut dilakukan guna menghilangkan berbagai kotoran hingga telur cacing yang tertinggal pada kulit atau kuku. ${ }^{7}$

Berdasarkan teori di atas, untuk memelihara kebersihan tangan, anak-anak harus mencuci tangan dengan sabun, baik saat makan, buang air besar dan bermain guna menghilangkan atau mengurangi mikroorganisme yang dapat menempel pada tangan. Hasil observasi di lapangan ditemukan bahwa tindakan yang dilakukan siswa SD Negeri 128 Pekanbaru menunjukkan masih adanya responden yang berisiko untuk terkena kecacingan seperti tidak Cuci Tangan Pakai Sabun (CTPS) sebelum dan sesudah mengkonsumsi makanan, serta setelah bermain tanah. Sebaiknya guru memberikan contoh dan teladan tentang cara membersihkan tangan dengan sabun dan menghimbau sekolah untuk menyediakan kran air atau wastafel untuk mencuci tangan agar siswa/i terbiasa untuk mencuci tangan baik sebelum dan setelah makan atau bermain. Selain itu, melengkapi sarana prasarana sekolah dengan menyediakan tempat cuci tangan portable dengan sabun di sekitar halaman kelas mungkin dapat dijadikan alternatif untuk meningkatkan kebiasaan cuci tangan dengan sabun.

\section{Hubungan Pakai Alas Kaki dengan Kecacingan pada Siswa SDN 128 Pekanbaru}

Berdasarkan hasil analisis data diketahui bahwa kebiasaan menggunakan pelindung atau alas kaki dengan kecacingan pada siswa SDN 128 Pekanbaru terdapat hubungan dengan nilai $\mathrm{p}=0,002(<0,05)$. Diketahui bahwa responden yang tidak memakai alas kaki berpeluang sebesar 11,7 kali lebih berisiko untuk terkena kecacingan. Sejalan dengan penelitian bahwa anak-anak yang jarang menggunakan alas kaki dan sanitasi yang buruk berisiko untuk mengalami kecacingan. ${ }^{10}$

Dalam penelitian ini ditemukan beberapa responden atau anak-anak yang enggan menggunakan penutup kaki atau alas kaki namun tidak mengalami kecacingan, karena ada faktor penunjang lainnya seperti pengetahuan dan informasi tentang kejadian kecacingan yang cukup baik yaitu responden mengatakan setelah selesai berolahraga tanpa memakai alas kaki mereka selalu membersihkan kakinya dengan sabun dan responden menyatakan pernah mengkonsumsi obat cacing. Hanya saja masih kurangnya kesadaran dalam pentingnya penggunaan alas kaki serta kurangnya kesadaran untuk merubah perilaku. Dianjurkan untuk selalu menggunakan alas kaki saat keluar rumah. Hal ini sangat berpengaruh terhadap pencegahan infeksi pada luka ataupun mencegah masuknya telur cacing ke dalam tubuh, serta mampu memutus mata rantai penyebaran penyakit ke dalam tubuh, sehingga mampu mencegah infeksi kecacingan.

Kecacingan di SDN 128 Pekanbaru bisa disebabkan karena masih ada aktivitas yang dilakukan siswa SD Negeri 128 Pekanbaru seperti tidak memakai alas kaki ketika olahraga di sekolah dan tidak memakai alas kaki ketika jam istirahat. Halaman sekolah sudah dipaving, tapi masih ada bagian yang masih tanah serta bersebelahan dengan lapangan bola, dimana anakanak biasa bermain dan berolahraga tanpa menggunakan alas kaki. Penggunaan pelindung kaki mampu mencegah terjadinya infeksi kecacingan. ${ }^{7}$ Menjaga kesehatan kaki sangat berpengaruh terhadap masuknya kuman ke dalam tubuh, salah satunya melalui larva ataui telur 
cacing. ${ }^{9}$ Peran guru dan orangtua diharapkan agar selalu mengingatkan untuk memakai alas kaki dimanapun mereka bermain agar tidak mudah terinfeksi cacingan. Perlu adanya kebijakan sekolah untuk mewajibkan penggunaan alas kaki saat anak-anak beraktivitas agar terhindar dari adanya risiko terjadinya infeksi cacing.

\section{Hubungan Kebersihan Kuku dengan Kecacingan di SDN 128 Pekanbaru}

Hasil analisis data menunjukkan bahwa kebersihan kuku dengan kecacingan pada siswa di SDN 128 Pekanbaru memiliki hubungan dengan $p$ value $=0,001 \quad(<0,05)$, Responden yang tidak menjaga kebersihan kuku berpeluang sebesar 20,5 kali lebih berisiko untuk terkena kecacingan dibandingkan pada anak yang menjaga kebersihan kuku. Hal ini juga didukung dengan penelitian dimana anak-anak dengan kuku yang tidak bersih atau tidak dipotong akan mudah terpapar infeksi cacing. ${ }^{10}$

Dampak dari kuku yang kotor dan panjang akan membuat tertinggalnya kotoran dan kuman penyebab penyakit. Pada kuku yang kotor dan panjang, biasanya akan ditemukan telur cacing. Idealnya kuku yang sehat, harus dipotong pendek dan bersih menggunakan potongan kuku untuk menghindari infeksi cacing dari kuku ke dalam mulut.

Hasil observasi di lapangan ditemukan bahwa tindakan yang dilakukan siswa SDN 128 Pekanbaru menunjukkan masih adanya responden yang berisiko untuk terkena penyakit kecacingan seperti memiliki kuku yang kotor hitam dan juga panjang. Dari penelitian ini terlihat bahwa ada responden yang menjaga kebersihan kuku tetapi mengalami kejadian kecacingan. Hal ini disebabkan karena faktor sering menggigit kuku dimana keadaan tangan tidak bersih sehingga memungkinkan masuknya telur cacing ke dalam mulut melalui perantara tangan. dan masuk ke usus halus.

Berdasarkan data dan teori diatas, kuku yang kotor dan jarangnya memotong kuku akan lebih mudah terinfeksi cacingan karena kemungkinan telur cacing berada di ujung kuku dan tertelan ketika makan dengan menggunakan tangan. Sebaiknya guru dan orang tua memeriksa kebersihan kuku anak setiap minggu agar tidak adalagi anak yang memiliki kuku yang panjang, hitam dan kotor sehingga mereka tidak mudah terinfeksi cacingan.

\section{Hubungan Jajan Sembarangan dengan Kejadian Kecacingan}

Berdasarkan hasil analisa data diketahui bahwa ada hubungan signifikan antara jajan sembarangan dengan kecacingan pada siswa di SDN 128 Pekanbaru dengan $p$ value $=0,003$ $(<0,05)$, responden yang tidak jajan sembarangan berpeluang 7,4 kali lebih kecil mengalami kecacingan. Hal ini juga didukung oleh penelitian tentang personal hygiene dengan cacingan pada anak di wilayah kerja Puskesmas Tamangapa Antang Makassar bahwa terdapat hubungan kebiasaan jajan dengan kejadian kecacingan $(P$ value $=0,001$ dan $\mathrm{OR}=39,0) .{ }^{11}$

Kebiasaan jajan sembarangan berisiko untuk meningkatkan timbulnya berbagai permasalahan kesehatan, terutama apabila tidak ada kontrol dari orang tua atau guru, jajanan yang tidak tertutup dan kotor, berkemunkinan membawa telur cacing sehingga akan dapat menjadi sumber penularan infeksi cacing pada anak-anak. Perilaku jajan tidak sehat berpengaruh terhadap kecacingan pada anak sebesar 40-60\%.

Berdasarkan data dan teori diatas, jajan yang tidak sehat, khususnya pada jajanan yang tidak terjamin kebersihannya seperti terbuka dan terpapar debu atau vektor lalat pembawa penyakit dapat meningkatkan risiko terjadinya infeksi penyakit kecacingan pada anak-anak. Jajanan tidak sehat berisiko berperan sebagai media penularan telur cacing. SDN 128 memiliki beberapa kantin di dalam sekolah, namun masih ditemukan pedagang jajanan di luar sekolah. Sebaiknya pihak sekolah dan orang tua lebih memperhatikan makanan yang akan di konsumsi anak dengan membuat peraturan agar membawa bekal dari rumah sehingga anak tidak jajan sembarangan dan tidak mudah terinfeksi cacingan dan memberikan informasi dan pemahaman bagi anak-anak tentang bahaya jajan sembarangan.

\section{Hubungan Bermain Tanah dengan Kejadian Kecacingan}

Kebiasaan bermain dengan tanah dengan kecacingan di SDN 128 Pekanbaru memiliki hubungan dengan $P$ value $=0,001(<0,05)$. Responden yang tidak bermain tanah berpeluang sebesar 23,8 kali lebih kecil untuk kecacinga. 
Sejalan dengan penelitian kecacingan pada Siswa SDN Kecamatan Rumbai Pesisir Pekanbaru. ${ }^{12}$

Infeksi cacing ditularkan melalui tanah tersebar di seluruh dunia dengan tingkat prevalensi tinggi di negara-negara tropis dan sub-tropis yang kekurangan fasilitas sanitasi, sistem pembuangan limbah yang tidak tepat, kurangnya pasokan air bersih, dan status sosial ekonomi yang rendah. Anak-anak usia sekolah terutama berisiko tinggi terhadap infeksi parasit usus ini. ${ }^{13}$ Anak yang sering bermain di tanah akan berisiko terinfeksi kecacingan. Hal ini disebabkan kondisi tanah yang lembab membuat cacing mudah berkembang biak dan ketika anak bermain di tanah maka anak dengan mudah terinfeksi cacing yang dapat melalui kulit atau mulut secara langsung. Tanah adalah media yang disukai cacing untuk berkembangbiak. Telur cacing ysng keluar bersama feses manusia akan menjadi infektif setelah berada di tanah. ${ }^{9}$

Fasilitas sanitasi yang baik akan sangat membantu dalam mencegah kontaminasi telur cacing ke dalam tubuh. Tanah yang hangat dan lembap merupakan tempat favorit cacing untuk berkembangbiak. ${ }^{14}$ Organisasi Kesehatan Dunia merekomendasikan program cacingan berbasis sekolah dengan komponen pendidikan higiene kesehatan.

Pemasaran sosial di tingkat masyarakat dan keterlibatan lebih lanjut dari orang tua anakanak dalam intervensi pendidikan berpotensi memaksimalkan perubahan perilaku dan mengarah pada pengurangan yang lebih besar pada beban infeksi STH di daerah endemis. ${ }^{15}$ Sangat penting untuk memberikan pendidikan kesehatan yang diperlukan kepada orang tua, sehingga anak-anak dapat dilindungi dari infeksi. ${ }^{16}$

Berdasarkan data dan teori di atas, siswa di SDN 128 Pekanbaru didukung oleh wilayah sekolah yang masih di kelilingi oleh lahan yang luas, termasuk lapangan bola, sehingga banyak anak-anak yang secara tidak langsung bermain dengan tanah. Pencegahan penularan cacing pada tanah, adalah dengan menggunakan fasilitas sanitasi dengan baik. ${ }^{16}$ Sebaiknya orang tua dan guru mengingatkan agar setelah bermain di tanah biasakan anak untuk mencuci tangan pakai sabun dan memakai alas kaki saat bermain agar telur cacing di tanah tersebut tidak masuk ke dalam tubuh dan bisa terhindar dari infeksi cacingan.

\section{KESIMPULAN}

Aktivitas cuci tangan pakai sabun, penggunaan alas kaki, menjaga kebersihan kuku, jajan sembarangan dan kebiasaan bermain tanah memiliki hubungan yang signifikan dengan kejadian kecacingan pada siswa di SDN 128 Pekanbaru. Selain penyuluhan, personal hygiene dan sanitasi lingkungan penting untuk diterapkan. Salah satunya adalah mengunjungi dokter setiap 6 bulan sekali. Diharapkan adanya kerja sama antara Dinas Kesehatan, Puskesmas dan pihak sekolah untuk memberikan pembinaan, penyuluhan, dan pemberian obat cacing berkala pada siswa sekolah dasar agar terhindar dari risiko penyakit kecacingan, termasuk program cacingan berbasis sekolah dengan komponen pendidikan higiene kesehatan.

\section{DAFTAR PUSTAKA}

1. DepKes RI Pedoman Umum Program Nasional Pemberantasan Cacingan di Era Desentralisasi. Jakarta: Depkes R.I; 2004.

2. World Health Organization. (2013). SoilTransmitted Helminth Infection:fact sheet No 366 updated June 2013, WHO; 2013.

3. Direktorat Jenderal PP \& PL Kemenkes RI. Profil Pengendalian Penyakit dan Penyehatan Lingkungan, Jakarta: Kementrian Kesehatan Republik Indonesia; 2012.

4. DinKes Kota Pekanbaru. Rekapitulasi Kasus Cacingan di Kota Pekanbaru, Pekanbaru: DKK; 2016.

5. Amalia, Astri Nur. 2017. Study of SoilTransmitted Helminthiasis Prevalence in School Childreen in Surabaya. Journal of Vocational Health Study 2017, 1(1): 23-26.

6. DepKes RI. Keputusan Menteri Kesehatan Republik Indonesia No.424/ MENKES/ SK/ VI/ 2006 Tentang Pedoman Pengendalian Cacingan,Jakarta : Depkes RI; 2006.

7. Sayoga. Pendidikan Kesehatan untuk Sekolah Dasar. Bandung: PT Remaja Rosda Karya; 2015.

8. Mumpuni, Yekti. 45 Penyakit yang Sering Hinggap pada Anak. Yogyakarta: Rapha Publishing; 2016 
9. Gandahusada, S., Ilahude, H., Pribadi, W. Parasitologi Kedokteran, Ed. VI; Jakarta:FKUI; 2006.

10. Samuel F, Demsew A, Alem Y, Hailesilassie Y. Soil Transmitted Helminthiasis and Associated Risk Factors Among Elementary School Children in Ambo Town, Western Ethiopia. BMC Public Health. 2017, Oct 10;17(1):791.

11. Irawati. Hubungan Personal Hygiene dengan Cacingan pada Anak di Wilayah Kerja Puskesmas Tamangapa Antang Makasar [Skripsi]. Makassar : Univ UIN Alauddin Makassar; 2013.

12. Kartini, Sri. Kejadian Kecacingan pada Siswa Sekolah Dasar Negeri Kecamatan Rumbai Pesisir Pekanbaru. Jurnal Kesehatan Komunitas 2016, Mei; 3(2): 53-58
13. WHO. Eliminating Soil-Transmitted Helminthiases as a Public Health Problem in Children: Progress Report 2001-2010 and Strategic Plan 2011-2020. WHO; 2012.

14. Garcia., Lynne, S. Diagnostik Parasitologi Kedokteran. Jakarta: EGC; 1996.

15. Gyorkos TW, Maheu-Giroux M, Blouin B, Casapia M. Impact of Health Education on Soil-Transmitted Helminth Infections in Schoolchildren of the Peruvian Amazon: A Cluster-Randomized Controlled Trial. PLoS Negl Trop Dis 2013; 7(9): e2397.

16. C. Muñoz-Antoli, A. Pavón, P. Pérez, R. Toledo, J.G. Esteban, Soil-transmitted Helminth Infections in Schoolchildren of Laguna de Perlas (Nicaragua), Journal of Tropical Pediatrics 2017, Apr; 63(2):124-134. 